\title{
Radioembolization for Hepatocellular Carcinoma: Evidence-Based Answers to Frequently Asked Questions
}

Bruno Sangro ${ }^{1,2 *}$ and Mercedes Iñarrairaegui ${ }^{1,2}$

${ }^{1}$ Liver Unit, Clinica Universitaria de Navarra

${ }^{2}$ Centro de Investigación Biomédica en Red de Enfermedades Hepáticas y Digestivas (CIBERehd), Pamplona, Spain

\begin{abstract}
Hepatocellular carcinoma ( $\mathrm{HCC}$ ) is the third most common cause of cancer-related mortality. Radioembolization is a form of selective internal radiation therapy that is increasingly used to treat patients with HCC, particularly those with more advanced disease. This review will try to answer some of the most frequently asked questions regarding the use of radioembolization to treat HCC patients and provide supporting evidence. Rather than a new form of transarterial chemoembolization (TACE), radioembolization is a form of brachytherapy that has a highly localized effect on liver tumors. The two devices that are available (glass and resin microspheres) are similar in size (25 to 35 microns), but differ in the amount of isotope loaded onto each microsphere and the number of spheres injected in a single treatment. Despite this, the evidence seems to indicate that the antitumor effect and safety profiles of these two devices in HCC are similar. Liver cirrhosis frequently underlies HCC. Despite the higher chance for relevant liver toxicity, there is now good evidence from large studies to show that radioembolization can be safely and effectively performed in cirrhotic patients with HCC. With no randomized controlled trials published so far, there is recent scientific evidence that allows comparison between radioembolization and other treatment options including TACE and the systemic, agent sorafenib. Radioembolization appears to have similar efficacy to TACE in patients that are ideal candidates for locoregional therapy and has shown encouraging results in patients that have failed TACE or who are poor candidates for this therapy. Survival in comparable sorafenib- and radioembolizationtreated HCC patients is quite similar. The indication for radioembolization has to be balanced against the risk of liver decompensation and the natural history of the disease, based on tumor burden and liver function. Patients with inadequate liver functional reserve and diffuse tumors affecting either lobes, or portal vein thrombosis that reaches the main trunk should probably not be treated with this procedure.
\end{abstract}

Keywords: Radioembolization; Hepatocellular carcinoma; Chemoembolization; Sorafenib; SIRT

\section{Introduction}

Hepatocellular carcinoma (HCC) is the sixth most common cancer in the world and the third most common cause of cancer-related mortality [1]. Eighty-five percent of the global burden of HCC occurs in developing countries with 5- to 10-times higher age-standardized incidence rates (world) in Eastern and South-Eastern Asia, and Middle and Western Africa than Northern Europe and USA (where rates are $\sim 4-5$ per 100,000) [1]. Cirrhotic patients of various etiologies and patients infected by viral hepatitis (hepatitis $\mathrm{C}$ virus $[\mathrm{HCV}]$ or chronic hepatitis $\mathrm{B}$ virus $[\mathrm{HBV}]$ ) are particularly prone to developing HCC. Even with active HCC surveillance of high-risk groups, less than $15 \%$ of all HCC patients are candidates for potentially curative therapies including surgical resection, liver transplantation or percutaneous ablation. For the majority of patients, either transarterial embolization (TAE) or chemoembolization (TACE) for intermediate stage disease [2] and/or sorafenib for more advanced stage disease has been shown to significantly prolong survival [3]. However, there is no universal agreement on the best candidates for these treatment options [4].

Radioembolization is a form of selective internal radiation therapy that is increasingly used to treat patients with HCC, particularly those with more advanced disease $[5,6]$. Since there is an increasing, but still limited, body of evidence published in the medical literature on this procedure, questions often arise. This review will try to answer some of the most frequently asked questions and provide supporting evidence.

\section{Is radioembolization a form of transarterial (chemo) embolization?}

Much like TACE, radioembolization utilizes the well-characterized dual vasculature of the liver to selectively treat HCC lesions that are almost exclusively supplied by blood from the hepatic arterial branches $[7,8]$. However, the mechanism of these two treatment modalities is very different. Radioembolization is in fact a form of brachytherapy and has a highly localized effect on liver tumors. While the liver is largely intolerant to whole liver radiation treatment, small portions of the liver can tolerate high-dose radiation exposure without significant complications, as long as sufficient normal liver is spared [9]. Commercially available microspheres for radioembolization are made of either resin (SIR-Spheres ${ }^{\circledR}$, Sirtex Medical Limited, Sydney, Australia) or glass (TheraSphere ${ }^{\circledR}$, Nordion, Ottawa, Canada). These small inert microspheres (measuring $\sim 25$ to 35 microns), loaded with the radionuclide yttrium-90 $\left({ }^{90} \mathrm{Y}\right)$, lodge within the peripheral neovasculature of tumors, where they deliver high-energy, betaradiation over a limited range (mean penetration of radiation into tissues is $2.4 \mathrm{~mm}$ ), thereby confining the tumoricidal dose to the immediate proximity of the tumor and sparing the normal liver parenchyma [10,11]. Bilbao and colleagues showed that resin microspheres have little or no embolic effect on medium to small arteries, so adequate oxygenation of the tumor tissue is maintained,

*Corresponding author: Bruno Sangro, MD, Liver Unit, Clínica Universitaria de Navarra, Avda, Pio XII 36. 31008 Pamplona, Spain, Tel: +34 948296 637; Fax: +34 948296 500; E-mail: bsangro@unav.es

Received April 26, 2011; Accepted May 26, 2011; Published June 15, 2011

Citation: Sangro B, Iñarrairaegui M (2011) Radioembolization for Hepatocellular Carcinoma: Evidence-Based Answers to Frequently Asked Questions. J Nucl Med Radiat Ther 2:110. doi:10.4172/2155-9619.1000110

Copyright: ( 2011 Sangro B, et al. This is an open-access article distributed unde the terms of the Creative Commons Attribution License, which permits unrestricted use, distribution, and reproduction in any medium, provided the original author and source are credited. 
increasing the lethal effect of the radiation [12]. In contrast, the larger TACE or bland embolization particles (100 to 500 microns in diameter) have been designed to occlude medium to large size arteries [13], so that ischemia drives the antitumor effect, with drug delivery (carried in lipiodol or drug-eluting beads) potentially enhancing tumor cell killing (Figure 1) [4].

The original concept for selective internal radiation therapy in HCC came from studies with lipiodol labeled with iodine-131 $\left({ }^{131} \mathrm{I}\right)$, a gamma- and beta-emitting radionuclide. Two randomized-controlled trials were conducted. The first compared ${ }^{131} \mathrm{I}$-labeled lipiodol with best supportive care in 27 patients with good liver function and multinodular or diffuse tumors and portal vein thrombosis [14]. Median survival was significantly prolonged with ${ }^{131}$ I-labeled lipiodol compared with best supportive care ( 24 weeks vs. 8 weeks, p<0.01) [14]. The second larger trial in 142 patients without portal vein thrombosis showed that compared with TACE (70 mg cisplatin), ${ }^{131}$ I-labeled lipiodol $(60 \mathrm{mCi}$; $2.2 \mathrm{GBq}$ ) was better tolerated with similar response rates (57\% vs. $64 \%)$ and 2 -year overall survival ( $42 \%$ vs. $38 \%)$ [15]. However, the clinical development of radioactive ${ }^{131} \mathrm{I}$-labeled lipiodol was hindered mainly by the need for radioprotection requiring the patient to remain isolated during the first 7 to 10 days after therapy. By contrast, microspheres are loaded with yttrium-90, a pure beta emitter with a short tissue penetration, which makes post-treatment isolation for radioprotection superfluous [16].

In conclusion, there are important differences in the mechanism of action between TACE/TAE and radioembolization (ischemia \pm chemotherapy $v s$. irradiation) that account not only for the diverse antitumor effect but also for differences in post-treatment imaging [17] as well as the safety profile [18]. Radioembolization produces minimal or no post-embolization syndrome, but if delivered to nontarget tissues can cause radiation-induced damage to the liver, lungs and gastrointestinal tract [19-21].

\section{Are there any differences in clinical outcome between glass and resin ${ }^{90} \mathrm{Y}$-loaded microspheres in HCC?}

Glass and resin microspheres, although similar in size (25 to 35 microns), differ in the amount of isotope loaded onto each microsphere (which is lower for resin spheres) and the number of spheres injected in a single treatment (which is typically lower for glass spheres). Despite this, the evidence (outlined below) would seem to indicate that the

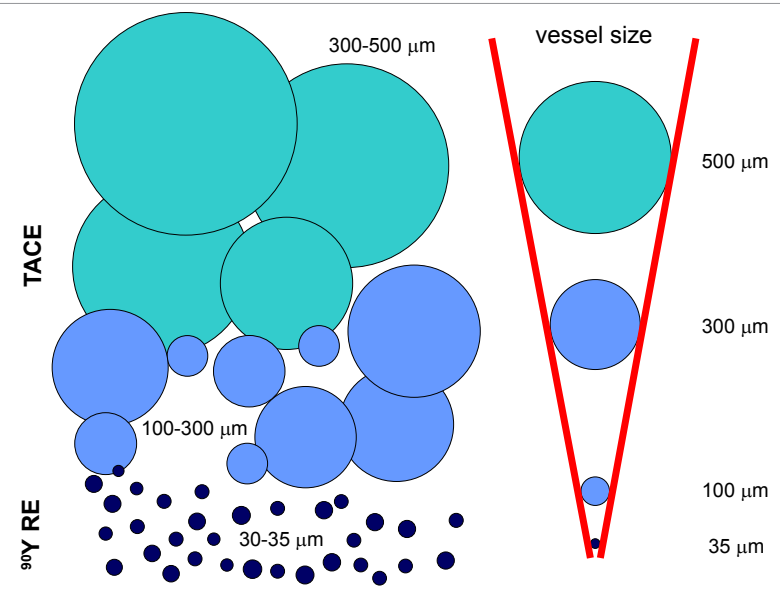

Figure 1: Differences in size and heterogeneity of particles used for TACE and radioembolization and the resulting impact on the size of the occluded vessel.

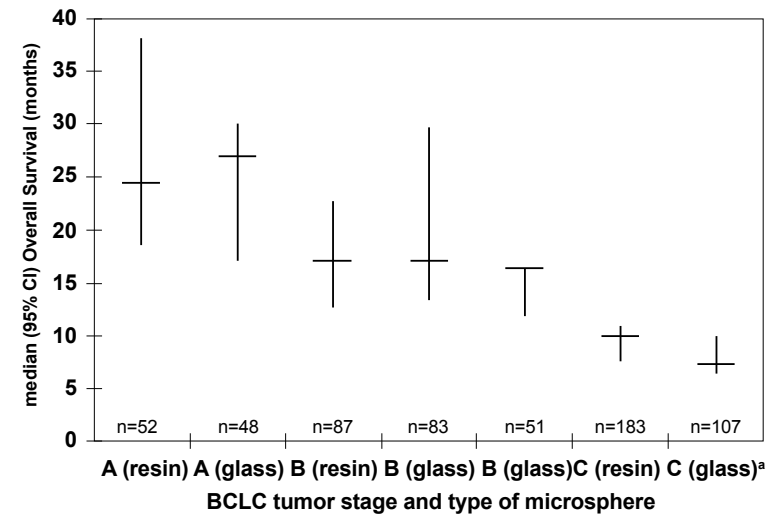

Figure 2: Overall survival by BCLC stage with ${ }^{90} \mathrm{Y}$ glass microspheres and ${ }^{90} \mathrm{Y}$ resin microspheres $[5,29]$

apatients in the advanced stage lacking extrahepatic disease.

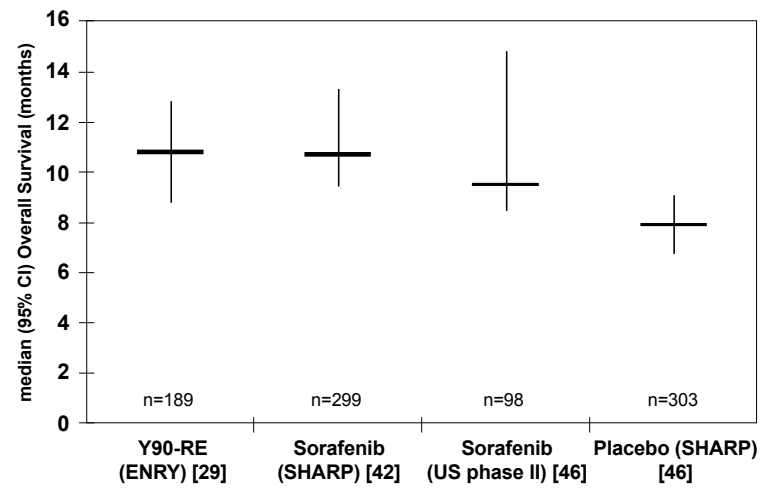

Figure 3: Overall survival reported for similar patients treated with radioembolization, sorafenib and placebo.

${ }^{90}$ Y-radioembolization: consecutive patients identified with Child-Pugh class $A$ and advanced stage disease (BCLC stage $C$ ) or had intermediate stage disease (BCLC stage $B$ ) and had failed prior vascular procedures (TACE; TAE) or were poor candidates for TACE [29].

Sorafenib (SHARP): patients randomized to the sorafenib arm in the SHARP trial [42]. Sorafenib (US phase II): patients with Child-Pugh class A class that received sorafenib in the US phase II study [46].

Placebo (SHARP): patients randomized to the placebo arm in the SHARP trial [42].

antitumor effect and safety profile of these treatment modalities in HCC are similar.

From a hemodynamic point of view, there were no major differences between the two microspheres in a computational model of a representative hepatic artery system, where laminar transient 3D particle-hemodynamics were simulated [22]. It could be argued that due to the higher number of microspheres typically used in a treatment with resin microspheres, a more intense ischemic effect would result. Some expert users say that incomplete delivery of the prescribed ${ }^{90} \mathrm{Y}$ activity is more frequent with resin microspheres. In fact, an analysis of a large cohort of 680 patients treated with resin microspheres worldwide found that the injected activity was only slightly inferior to prescribed activity (prescribed: $1.2 \pm 0.6 \mathrm{GBq}$; administered: $1.1 \pm 0.6$ ) [23]. It could also be argued that for the same reason it would be difficult to administer the full prescribed activity to small single lesions with resin microspheres or that the number of radiation sources would be 
too small for a very large tumor to be treated with glass microspheres. However, post-treatment imaging by SPECT or positron-emission tomography challenges this argument [24].

If there are differences in the injection procedure and intravascular behavior, they do not seem to translate into differences in antitumor effect. Tumor response rates vary from $20 \%$ [25] to $42 \%$ [26] for glass microspheres, and from 23\% [27] to 44\% [28] for resin microspheres. Overall survival was remarkably similar when patients were stratified by tumor stage in two of the largest series of patients with HCC studied so far (Figure 2) $[26,29,30]$.

\section{Does the presence of cirrhosis in HCC affect the outcome following radioembolization?}

Cirrhosis, characterized by the replacement of liver tissue by fibrosis and regenerative nodules, produces a notable distortion in the vascular anatomy of the liver. These changes have two important consequences for the treatment of patients with a cirrhotic liver, namely changes in the usual distribution of the microspheres and a reduction in the functional liver reserve. Portal triads can no longer be identified in the cirrhotic liver and disordered vessels may traverse the fibrotic septa that separate regenerative nodules. In the advanced stages of cirrhosis, intrahepatic anastomosis can develop between the terminal arterioles, portal venules and hepatic venules [31].

Little data have been obtained so far from animal models or human studies on the impact of these changes on the distribution of microspheres to normal tissue. Certainly, lung shunting is more prevalent in cirrhotic than non-cirrhotic livers, independent of the volume of tumor tissue treated [32]. This adverse event can be largely prevented by keeping the threshold for lung irradiation below 30 Gy, although this inevitably reduces the number of microspheres available for tumor targeting and could theoretically reduce treatment effectiveness.

Of much greater importance is the reduced functional reserve and impaired regenerative ability of the cirrhotic liver. Both these factors increase the risk of liver failure, especially for patients who have had prior extensive resection, or liver insult from toxins, acute viral hepatitis or external irradiation [33]. Direct liver cell injury and further compromised liver blood supply by direct damage to the vasculature could increase the risk of clinically relevant liver toxicity in cirrhotic compared with non-cirrhotic livers after radioembolization.

Despite the higher chance for reduced microsphere availability and relevant liver toxicity, there is now good evidence from large studies to show that radioembolization can be safely and effectively performed in cirrhotic patients with HCC. Response rates are consistently in the range of $30 \%$ to $50 \%$ [4] and overall survival following radioembolization was not significantly different in patients with cirrhotic and non-cirrhotic livers (Hazard ratio: 1.26 [95\% confidence interval [CI] $0.89-1.77$; $\mathrm{p}=0.19])$ [29].

Radioembolization-induced liver disease, defined as jaundice and ascites appearing 4 to 8 weeks after radioembolization in the absence of clear tumor progression, was described as Grade 4 in $2.5 \%$ of HCC patients treated in a single institution [34] and grade 3 increases in bilirubin (according to CTCAE [35]) were described in less than $6 \%$ of patients in a European multicenter study independent of their basal tumor stage and treatment design [29].

\section{How does the clinical outcome for radioembolization compare with TACE?}

Rough comparisons of survival between retrospective series of patients treated with TACE or radioembolization are meaningless if the target populations differ. At least in Western countries, radioembolization is in most cases indicated for patients who are considered poor candidates for TACE. Typical candidates for radioembolization are either:

i. patients with advanced stage disease with portal vein invasion but no extrahepatic metastases;

ii. patients with intermediate stage disease but too many nodules involving both lobes to be treated by TACE in a selective fashion; or

iii. patients with intermediate stage disease who have failed to respond to TACE and have ongoing disease progression in the liver or active tumor following TACE.

The ratio of each of these three subgroups differs with each published series $[18,36,37]$. Any blind comparison with TACE is basically irrelevant because TACE cohorts usually include patients that have early stage disease and tumors that cannot be treated with radical therapies because of age, tumor size and location, cirrhosis or comorbidities, or intermediate-stage disease with a limited number of tumors that can be selectively embolized (avoiding occlusion of the main lobar arteries) [4]. However, the inclusion criteria for TACE in some centers has broadened beyond the evidence base in intermediatestage disease [2] to include patients with more advanced disease. In a randomized controlled trial of 138 patients by Doffoël and colleagues [38] which included advanced cases ( $48 \%$ had an ECOG $>0,49 \%$ had bilobar disease and $9 \%$ had segmental portal vein thrombosis), median overall survival was 13.8 months (95\% CI, 7.6-16.8) with conventional TACE plus tamoxifen and 11.0 months (95\% CI, 7.3-15.1) with tamoxifen alone.

Over the last 12 months, three different groups have published outcomes of patients treated in routine clinical practice using TACE or radioembolization in cohorts with either early or intermediate tumors [18], or a mixture of patients with more advanced tumors [36,37] Each analysis found equivalent or better survival for patients receiving

\begin{tabular}{|l|l|l|l|l|l|l|l|}
\hline Series & \multicolumn{3}{l|l}{ Salem et al. [18] } & \multicolumn{2}{l|}{ Carr et al. [36] } & \multicolumn{2}{l|}{ Kooby et al. [37] } \\
\hline Group & TACE & RE & TACE & RE & \multicolumn{1}{l|}{ TACE $^{3}$} & RE \\
\hline Number of patients & 122 & 123 & 691 & 99 & 44 & 27 \\
\hline Period & $2001-$ & $2001-$ & $1999-$ & $2000-$ & $1996-$ & $2003-$ \\
& 2010 & 2010 & 2000 & 2005 & & \\
\hline Viral etiology (\%) & 58 & 50 & 34 & 39 & $57^{\text {a }}$ & $37^{\text {a }}$ \\
\hline Cirrhosis (\%) & 92 & 86 & 66 & 80 & $\mathrm{nr}$ & $\mathrm{nr}$ \\
\hline Solitary tumors (\%) & 47 & 45 & $\mathrm{nr}$ & $\mathrm{nr}$ & 57 & 44 \\
\hline > 5 nodules (\%) & $\mathrm{nr}$ & $\mathrm{nr}$ & 37 & 26 & $\mathrm{nr}$ & $\mathrm{nr}$ \\
\hline Portal vein thrombosis (\%) & 0 & 0 & 42 & 28 & 30 & 52 \\
\hline Bilobar disease (\%) & 34 & 36 & 51 & 43 & $30^{\mathrm{b}}$ & $30^{\mathrm{b}}$ \\
\hline Child A (\%) & 55 & 54 & $\mathrm{nr}$ & $\mathrm{nr}$ & 50 & 48 \\
\hline BCLC tumor stage (\%) & & & & & & \\
\hline Early (A) & 39 & 35 & $\mathrm{nr}$ & $\mathrm{nr}$ & $\mathrm{nr}$ & $\mathrm{nr}$ \\
\hline Intermediate (B) & 20 & 28 & $\mathrm{nr}$ & $\mathrm{nr}$ & $\mathrm{nr}$ & $\mathrm{nr}$ \\
\hline Advanced (C) & 9 & 10 & $\geq 42$ & $\geq 28$ & $\geq 30$ & $\geq 52$ \\
\hline $\begin{array}{l}\text { Median overall survival } \\
\text { (months) }\end{array}$ & 17.4 & $20.5^{\mathrm{c}}$ & 8.5 & $11.5^{\mathrm{d}}$ & 6.0 & $6.0^{\mathrm{e}}$ \\
\hline
\end{tabular}

TACE: transarterial chemoembolization. RE: radioembolization. ${ }^{1}$ mitomycin $\mathrm{C}+$ doxorubicin + cisplatin mixed with lipiodiol and followed by calibrated particles: ${ }^{2}$ Gelfoam or calibrated particles avoiding stasis followed by cisplatin without lipiodol. ${ }^{3}$ doxorubicin + cisplatin + mitomycin-C followed by PVA particles. nr: not reported. ${ }^{a}$ : HCV only; ${ }^{b}$ : aprox (as per the text); ${ }^{c} p=0.232 ;{ }^{d} p=0.014 ;{ }^{e} p=0.7$ Table 1: Results from comparative series of HCC patients treated by TACE and radioembolization $[18,36,37]$ 
radioembolization compared with broadly matched patients allocated to TACE (Table 1). In other case series evaluations analyzed by BCLC (Barcelona Clinic Liver Cancer) stage of disease for treatment using TACE $(n=172)$ [39], ${ }^{90} Y$-glass microspheres $(n=291)$ [5] or ${ }^{90} Y$-resin microspheres $(n=325)$ [29], the following median overall survivals in months $(95 \% \mathrm{CI})$ were reported in early (BCLC stage A) disease: 40 (15-46), 26.9 (17-30.2) and 24.4 (18.6-38.1); intermediate (BCLC stage B) disease: 17.4 (13.9-18.8), 17.2 (13.5-29.6) and $16.9(12.8-22.8)$ and advanced (BCLC stage C) disease: 6.6 (4-9.3), 7.3 (6.5-10.1) for glass microspheres in patients with no extra-hepatic disease and 5.4 (2.7-7.5) in those with extra-hepatic disease, and 10.0 (7.7-10.9), respectively. The overlapping confidence intervals indicate that radioembolization and TACE have broadly similar benefits in terms of overall survival. According to Salem and colleagues [18], a trial of more than 1,000 patients would be required in order to demonstrate equivalence between these therapies. Therefore a head-to-head comparison between radioembolization and TACE is impractical in this disease setting.

Importantly, the ability to down-stage patients that are beyond those criteria used for the indication of radical therapies (transplantation, resection or ablation) and are finally treated with these options was superior for radioembolization than for TACE [40] and results in longterm survival in most patients successfully down-staged [41].

In summary, radioembolization appears to have similar efficacy to TACE in patients that are ideal candidates for local-regional therapy and has shown encouraging results in patients that have failed TACE or who are poor candidates for this therapy.

\section{How does radioembolization compare with sorafenib?}

The comparisons with the multi-tyrosine kinase inhibitor sorafenib are more straightforward. Most radioembolization series include patients who have progressed or relapsed after locoregional therapies, such as TACE or bland embolization, or were considered poor candidates for these locoregional therapies due to the presence of portal vein invasion or bulky tumors. The finding that the multityrosine kinase inhibitor sorafenib prolonged survival in a very similar population of patients with mixed intermediate and advanced stage HCC [42] has led to its increasing use since 2008. The main difference between radioembolization series and sorafenib trials is the higher percentage of patients with extrahepatic disease in the sorafenib clinical trials, particularly in the Asia-Pacific trial [43].

In the absence of survival data from direct comparative trials with radioembolization and sorafenib, a recent retrospective analysis has compared radioembolization as first-line treatment with a control group matched for liver function and tumor burden, treated with conventional or experimental therapies or no therapy [44]. In this well-matched comparison, survival was significantly better with radioembolization than the control arm (16 vs. 8 months; $\mathrm{p}<0.05)$ even when adjusted for cirrhosis, vascular invasion, multinodularity, or bilobar involvement. This preliminary evidence illustrates that radioembolization can prolong survival over no specific therapy in a population of patients not amenable for TACE. This is supported by numerous studies reporting survivals in the range of 9 to 16 months with radioembolization $[5,25,27,29,30,45]$ among patients who had similar characteristics to the patients who were randomized to placebo in the SHARP trial and who had a median survival of 7.9 months [29]. Figure 3 illustrates overall survival of the patients following radioembolization within a European multicenter series [29], approximately $60 \%$ of whom met the inclusion criteria for SHARP, the sorafenib and placebo arms of the SHARP trial [42], and the sorafenib arm of a phase II trial conducted in the US [46]. The Figure illustrates the significant overlap in 95\% confidence intervals between the sorafenib- and radioembolization-treated groups. Phase III trials comparing sorafenib and radioembolization or their combination are now ongoing.

\section{When should patients not be treated with radioembolization?}

A recent European series has provided an in-depth analysis of the prognostic factors among 325 consecutive patients with mostly advanced-stage HCC who received radioembolization at eight centers between September 2003 and December 2009 [29]. Prognosis was driven by liver function (as measured by individual variables such as INR or bilirubin levels or by composite variables such as the Child-Pugh score) and tumor burden (as measured by nodularity, portal vein thrombosis, alpha-fetoprotein levels, distant metastases or performance status) [29]. Individual predictors of survival in a multivariate model were: an INR level greater than 1.2, an Eastern Cooperative Oncology Group (ECOG) score higher than ' 0 ', more than 5 nodules and extrahepatic disease [29]. Not surprisingly, subgroups of patients from a different series [5] with Child-Pugh class B, portal vein thrombosis, advanced (BCLC stage ' $C$ ') disease and/or extrahepatic disease were also found to have a very poor prognosis (median overall survival less than 6 months). Similar findings were reported by Kulik et al. [47] among patients with portal vein thrombosis of the main trunk who had a median survival of 6 months [48].

The importance of tumor burden and liver function in predicting poor survival following radioembolization accords with the early experience in North America where 3-month mortality was associated with infiltrative tumors, bulky disease, highly increased transaminases ( $5 \mathrm{xUNL}$ ), tumor volume $\geq 50 \%$ with albumin $\leq 3 \mathrm{~g} / \mathrm{dL}$, and bilirubin $\geq 2 \mathrm{mg} / \mathrm{dL}$ [5]. As a result, although this is not level 1 evidence coming from controlled trials, treatment with radioembolization is probably not appropriate for those patients that have a bilirubin higher than $1.5 \mathrm{mg} / \mathrm{dL}$ or an INR higher than 1.2 (that reflect a reduced functional liver reserve) and also have either diffuse, ill-defined tumors affecting both lobes, or portal vein thrombosis that reaches the main trunk. Radioembolization should be formally contraindicated for those patients with decompensated cirrhosis (Child-Pugh score higher than '7').

\section{References}

1. GLOBOCAN (2008) International Agency for Research on Cancer and WHO http://globocan.iarc.fr/ Accessed: April 2011.

2. Llovet JM, Bruix J (2003) Systematic review of randomized trials fo unresectable hepatocellular carcinoma: Chemoembolization improves survival Hepatology 37: 429-442.

3. Llovet JM, Ricci S, Mazzaferro V, Hilgard P, Gane E, et al. (2008) Sorafenib in advanced hepatocellular carcinoma. N Engl J Med 359: 378-390.

4. Sangro B, D'Avola D, Iñarrairaegui M, Prieto J (2011) Transarterial therapies for hepatocellular carcinoma. Expert Opin Pharmacother 12: 1057-1073.

5. Salem R, Lewandowski RJ, Mulcahy MF, Riaz A, Ryu RK, et al. (2010) Radioembolization for hepatocellular carcinoma using yttrium-90 microspheres: a comprehensive report of long-term outcomes. Gastroenterology 138: 52-64.

6. Sangro B, Carpanese L, Cianni R, Golfieri R, Gasparini D, et al (2011) Survival and tolerability following ${ }^{90} \mathrm{Y}$-resin microsphere radioembolisation in patients with unresectable BCLC stage ' $C$ ' hepatocellular carcinoma. 46 ${ }^{\text {th }}$ Annual Meeting of the European Association for the Study of the Liver (EASL), Berlin, Germany, J Hepatol 54: S262-263.

7. Matsui O, Kadoya M, Kameyama T, Yoshikawa J, Takashima T, et al. (1991) Benign and malignant nodules in cirrhotic livers: distinction based on blood supply. Radiology 178: 493-497. 
Citation: Sangro B, Iñarrairaegui M (2011) Radioembolization for Hepatocellular Carcinoma: Evidence-Based Answers to Frequently Asked Questions. J Nucl Med Radiat Ther 2:110. doi:10.4172/2155-9619.1000110

8. Conway JG, Popp JA, Thurman RG (1985) Microcirculation of hepatic nodules from diethylnitrosamine-treated rats. Cancer Res 45: 3620-3625.

9. Jackson A, Ten Haken RK, Robertson JM, Kessler ML, Kutcher GJ et al. (1995) Analysis of clinical complication data for radiation hepatitis using a paralle architecture model. Int J Radiat Oncol Biol Phys 31: 883-891.

10. Kennedy AS, Nutting C, Coldwell D, Gaiser J, Drachenberg C (2004) Pathologic response and microdosimetry of ${ }^{90} \mathrm{Y}$ microspheres in man: review of four explanted whole livers. Int J Radiat Oncol Biol Phys 60: 1552-1563.

11. Campbell AM, Bailey IH, Burton MA (2000) Analysis of the distribution of intraarterial microspheres in human liver following hepatic yttrium-90 microsphere therapy. Phys Med Biol 45: 1023-1033.

12. Bilbao JI, de Martino A, de Luis E, Díaz-Dorronsoro L, Alonso-Burgos A, et al. (2009) Biocompatibility, inflammatory response, and recannalization characteristics of nonradioactive resin microspheres: histological findings. Cardiovasc Intervent Radiol 32: 727-736.

13. Bilbao JI, De Luis, E, Garcia de Jalon JA, de Martino A, Lozano MD, et al. (2008) Comparative study of four different spherical embolic particles in an animal model: A morphologic and histologic evaluation. J Vasc Interv Radiol 19: $1625-1638$

14. Raoul JL, Guyader D, Bretagne JF, Duvauferrier R, Bourguet P, et al. (1994) Randomized controlled trial for hepatocellular carcinoma with portal vein thrombosis: intra-arterial iodine-131-iodized oil versus medical support. J Nucl Med 35: 1782-1787.

15. Raoul JL, Guyader D, Bretagne JF, Heautot JF, Duvauferrier R, et al. (1997) Prospective randomized trial of chemoembolization versus intra-arterial injection of ${ }^{131}$-labeled-iodized oil in the treatment of hepatocellular carcinoma. Hepatology 26: 1156-1161.

16. Gulec SA, Selwyn R, Weiner R, Flamen P, Mesoloras G, et al. (2009) Radiomicrosphere therapy: nuclear medicine considerations, guidelines and protocols. J Intervent Oncol 2: 26-39.

17. Ibrahim SM, Nikolaidis P, Miller FH, Lewandowski RJ, Ryu RK, et al (2009) Radiologic findings following Y90 radioembolization for primary liver malignancies. Abdom Imaging 34: 566-581.

18. Salem R, Lewandowski RJ, Kulik L, Wang E, Riaz A, et al. (2011) Radioembolization results in longer time-to-progression and reduced toxicity compared with chemoembolization in patients with hepatocellular carcinoma. Gastroenterology 140: 497-507.

19. Sangro B, Gil-Alzugaray B, Rodriguez J, Sola I, Martinez-Cuesta A, et al (2008) Liver disease induced by radioembolisation of liver tumors: description and possible risk factors. Cancer 112: 1538-1546.

20. Carretero C, Munoz-Navas M, Betes M, Angos R, Subtil JC, et al. (2007) Gastroduodenal injury after radioembolization of hepatic tumors. Am J Gastroenterol 102: 1216-1220.

21. Riaz A, Lewandowski RJ, Kulik LM, Mulcahy MF, Sato KT, et al. (2009) Complications following radioembolization with yttrium-90 microspheres: a comprehensive literature review. J Vasc Interv Radiol 20: 1121-1130.

22. Basciano CA, Kleinstreuer C, Kennedy AS, Dezarn WA, Childress E (2010) Computer modeling of controlled microsphere release and targeting in representative hepatic artery system. Ann Biomed Eng 38: 1862-1879.

23. Kennedy AS, McNeillie P, Dezarn WA, Nutting C, Sangro B, et al. (2009) Treatment parameters and outcome in 680 treatments of internal radiation with resin ${ }^{90}$ Y-microspheres for unresectable hepatic tumors. Int J Radiat Oncol Bio Phys 74: 1494-1500.

24. Gates VL, Esmail AA, Marshall K, Spies S, Salem R (2011) Internal pair production of ${ }^{90} \mathrm{Y}$ permits hepatic localization of microspheres using routine PET: proof of concept. J Nucl Med 52: 72-76.

25. Dancey JE, Shepherd FA, Paul K, Sniderman KW, Houle S, et al. (2000) Treatment of nonresectable hepatocellular carcinoma with intrahepatic ${ }^{90}$ Y-microspheres. J Nucl Med 41: 1673-1681.

26. Salem R, Lewandowski RJ, Mulcahy MF, Riaz A, Ryu RK, et al. (2010) Radioembolization for hepatocellular carcinoma using Yttrium-90 microspheres: a comprehensive report of long-term outcomes. Gastroenterology 138: 52-64.

27. Sangro B, Bilbao JI, Boan J, Martinez-Cuesta A, Benito A, et al. (2006) Radioembolization using ${ }^{90} \mathrm{Y}$-resin microspheres for patients with advanced hepatocellular carcinoma. Int J Radiat Oncol Biol Phys 66: 792-800.
28. Lau W, Leung W, Ho S, Leung NW, Chan M, et al. (1994) Treatment of hepatocellular carcinoma with intra-hepatic arterial yttrium-90 microspheres: a phase I and II study. Br J Cancer 70: 994-999.

29. Sangro B, Ettorre G, Cianni R, Gasparini D, Golfieri R, et al (2011) European network on radioembolisation with ${ }^{90} \mathrm{Y}$-resin microspheres (ENRY) multicentre evaluation of survival, safety and liver function for unresectable hepatocellular carcinoma (HCC). 46 $6^{\text {th }}$ Annual Meeting of the European Association for the Study of the Liver (EASL), Berlin, Germany, March 30-April 3, 2011; J Hepatol 54: S36.

30. Hilgard P, Hamami M, Fouly AE, Scherag A, Müller S, et al. (2010) Radioembolization with yttrium-90 glass microspheres in hepatocellular carcinoma: European experience on safety and long-term survival. Hepatology 52: $1741-1749$

31. Villeneuve JP, Dagenais M, Huet PM, Roy A, Lapointe R, et al. (1996) The hepatic microcirculation in the isolated perfused human liver. Hepatology 23 24-31

32. Kennedy A, Coldwell D, Sangro B, Wasan H, Salem R (2010) Radioembolization for the treatment of liver tumors: general principles. Am J Clin Oncol 3: 73-81.

33. Furuse J, Ishii H, Nagase M, Kawashima M, Ogino T, et al. (2005) Adverse hepatic events caused by radiotherapy for advanced hepatocellular carcinoma. J Gastroenterol Hepatol 20: 1512-1518.

34. Sangro B, Iñarrairaegui M, D'Avola D, Bilbao JI, Rodriguez J, et al. (2009) Toxicity of Y90-radioembolisation resulting from radiation of non-targe tissues. $3^{\text {rd }}$ International Liver Cancer Association (ILCA) meeting, Milan, Italy, September 4-6.

35. Cancer Therapy Evaluation Program, Common Terminology Criteria for Adverse Events, Version 3.0, DCTD, NCl, NIH, DHHS March 31, 2003 (Available a http://ctep.cancer.gov Published: August 9, 2006).

36. Carr BI, Kondragunta V, Buch SC, Branch RA (2010) Therapeutic equivalence in survival for hepatic arterial chemoembolization and yttrium 90 microsphere treatments in unresectable hepatocellular carcinoma: a Two-Cohort Study. Cancer 116: 1305-1314.

37. Kooby DA, Egnatashvili V, Srinivasan S, Chamsuddin A, Delman KA, et al. (2010) Comparison of yttrium-90 radioembolization and transcatheter arterial chemoembolization for the treatment of unresectable hepatocellular carcinoma. J Vasc Interv Radiol 21: 224-230

38. Doffoël M, Bonnetain F, Bouché O, Vetter D, Abergel A, et al. (2008) Multicentre randomised phase III trial comparing Tamoxifen alone or with Transarterial Lipiodol Chemoembolisation for unresectable hepatocellular carcinoma in cirrhotic patients (Fédération Francophone de Cancérologie Digestive 9402) Eur J Cancer 44: 528-538.

39. Lewandowski RJ, Mulcahy MF, Kulik LM, Riaz A, Ryu RK, et al. (2010) Chemoembolization for hepatocellular carcinoma: comprehensive imaging and survival analysis in a 172-patient cohort. Radiology 255: 955-965.

40. Lewandowski RJ, Kulik LM, Riaz A, Senthilnathan S, Mulcahy MF, et al (2009) A comparative analysis of transarterial downstaging for hepatocellula carcinoma: chemoembolization versus radioembolization. Am J Transplant 9: 1920-1928.

41. Iñarrairaegui M, D'Avola D, Bilbao JI, Pardo F, Benito A, et al (2010) 90Y radioembolization down-stage HCC UNOS stage T3 to radical treatments with prolonged survival. $4^{\text {th }}$ International Liver Cancer Association (ILCA) meeting, Montreal, Quebec, Canada Abstract P132, p 56.

42. Llovet J, Ricci S, Mazzaferro V, Hilgard P, Gane E, et al. (2008) Sorafenib in advanced hepatocellular carcinoma. N Engl J Med 359: 378-390.

43. Cheng AL, Kang YK, Chen Z, Tsao CJ, Qin S, et al. (2009) Efficacy and safety of sorafenib in patients in the Asia-Pacific region with advanced hepatocellula carcinoma: a phase III randomised, double-blind, placebo-controlled trial. Lancet Oncol 10: 25-34.

44. D’Avola D, Lñarrairaegui M, Bilbao JI, Martinez-Cuesta A, Alegre F, et al. (2009) A retrospective comparative analysis of the effect of $Y 90$-radioembolization on the survival of patients with unresectable hepatocellular carcinoma. Hepatogastroenterology 56: 1683-1688.

45. Lau W, Ho S, Leung T, Chan M, Ho R et al. (1998) Selective Internal Radiation Therapy for nonresectable hepatocellular carcinoma with intraarterial infusion of 90-yttrium microspheres. Int J Radiat Oncol Biol Phys 40: 583-592.

46. Abou-Alfa GK, Schwartz L, Ricci S, Amadori D, Santoro A, et al. (2006) Phase II study of sorafenib in patients with advanced hepatocellular carcinoma. J Clin Oncol 24: 4293-4300. 
Citation: Sangro B, Iñarrairaegui M (2011) Radioembolization for Hepatocellular Carcinoma: Evidence-Based Answers to Frequently Asked Questions. J Nucl Med Radiat Ther 2:110. doi:10.4172/2155-9619.1000110

Page 6 of 6

47. Kulik LM, Carr BI, Mulcahy MF, Lewandowski RJ, Atassi B, et al. (2008) Safety and efficacy of ${ }^{90} \mathrm{Y}$ radiotherapy for hepatocellular carcinoma with and without portal vein thrombosis. Hepatology 47: 71-81.
48. Goin JE, Salem R, Carr BI, Dancey JE, Soulen MC, et al. (2005) Treatment of unresectable hepatocellular carcinoma with intrahepatic yttrium 90 microspheres: a risk-stratification analysis. J Vasc Interv Radiol 16: 195-203. 